\title{
The effects of electricity price changes on prices of other goods and services - evidence from Turkey
}

\author{
Ahmet Gedikkaya ${ }^{a}$, Serdar Varlik ${ }^{\mathrm{b}}$ and Berument M. Hakan $\mathbb{D}^{\mathrm{c}}$

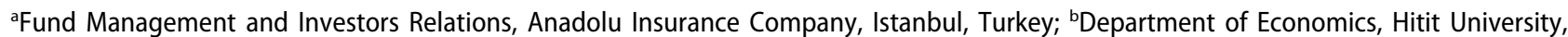 \\ Corum, Turkey; 'Department of Economics and Energy Policy Research Center, Bilkent University, Ankara, Turkey
}

ABSTRACT

This article employs a Factor-Augmented Vector Autoregressive model to assess the effects of electricity price innovations on prices of other goods and services. Using monthly series from Turkish Domestic Producer Price Index (D-PPI) and Harmonized Index of Consumer Prices (HICP) components, the results from the analyses on D-PPI components suggest that (i) Machinery \& Equipment (not elsewhere classified); Electrical Equipment; and Rubber \& Plastic Products increase the most, while (ii) Tobacco Products; Crude Petroleum \& Natural Gas; and Water Supply, Sewerage, Waste Management \& Remediation Services increase the least. In addition, the results from the analyses on HICP components suggest that (iii) Housing, Water, Electricity, Gas \& Other Fuels; Furnishings, Household Equipment \& Maintenance; and Restaurants \& Hotels increase the most, while (iv) Communications; Alcoholic Beverages, Tobacco \& Narcotics; and Education increase the least.

\section{KEYWORDS}

Electricity prices; inflation; pass-through; FAVAR

JEL CLASSIFICATION Q43; E31; 013

\section{Introduction}

Electricity prices constitute a significant element in the price formation of each sector in the whole economy. The purpose of this article is to assess the effects of electricity price on components of consumer and producer prices while allowing the interaction among these prices.

There are various methods to assess the effects of electricity price on prices of other goods such as Lim and Yoo's (2013) the Input-Output (I-O) price model; Akkemik's (2011) Social Accounting Matrix as a version of I-O tables; He et al.'s (2010) CGE framework; and Mjelde and Bessler's (2009) Vector Error Correction Model.

This study requires the employment of a large data set comprising prices of a sizable number of goods and services; thus, we employ FactorAugmented Vector Autoregressive (FAVAR) model of Bernanke, Boivin and Eliasz (2005) which combines the standard VAR model with dynamic factor analysis employed by Stock and Watson (1998). Using a FAVAR model provides a number of advantages: (i) It is a dynamic model such that we observe the effect of electricity price innovations over time. It allows us to evaluate the effects on various prices simultaneously, which in turn enables us to observe the interrelations among various prices. (ii) it includes large data sets reduced to a few factors without any big loss of information.

We perform the econometric analyses by using the Turkish data. Using Turkish data has various advantages. First, the volatile electricity prices and inflation rates of Turkey increase the power of our hypotheses tests through reducing the probability of type-II error. ${ }^{1}$ Second, the small number of regulated prices of goods \& services and the close proximity of electricity prices to be determined exogenously in the Turkish economy also conserve our analysis from unrealistic references. Third, Turkey is one of the leading emerging market economies with its seventeenth place in the world. In the period between 2004 and 2016, the average growth rates of Turkish GDP per capita and installed power are $4.2 \%$ and $6.3 \%$, respectively. ${ }^{2}$ Forth, considering Turkey's first place on electricity production growth rate in

\footnotetext{
CONTACT Berument M. Hakan $\otimes$ berument@bilkent.edu.tr

${ }^{1}$ To be precise, the standard deviations of the monthly inflation of the CPI electricity and HICP are both 3.38, it is 2.06 for HICP all items and 2.2 for D-PPI general in the period between 1996 and 2018.

${ }^{2}$ World Bank Data and Electricity Generation - Transmission Statistics of Turkey published by TEIAS.

○ 2019 Informa UK Limited, trading as Taylor \& Francis Group
} 
Europe and third place in the world ${ }^{3}$ and its high reliance on natural gas in electricity production ${ }^{4}$ as well as being the second most natural gas importer in the Western European market from Russia $^{5}$, Turkey proves itself to be a unique laboratory environment to assess the effect of electricity prices on a set of consumer and producer prices. Fifth, the recent reforms and deregulations in the electricity market of Turkey and the trend of privatization constitute a benchmark characteristic to this study in order to make inferences on the other emerging countries.

The results from the analyses on Domestic Producer Price Index (D-PPI) components suggest that the highly electricity-dependent sectors respond to the electricity price shocks than the less electricity-dependent sectors. In addition, the results from the analyses on the Harmonized Index of Consumer Prices (HICP) components suggest that the goods \& services which have high-demand elasticity of price respond less to the electricity price shocks.

The outline of the article is as follows: SectionII presents the econometric framework. Then, SectionIII reports the empirical evidence, and SectionIV presents the conclusion.

\section{Methodology}

Let $X_{t}$ be the $N \times 1$ vector of informational time series, $Y_{t}$ be an $M \times 1$ vector of observable economic variables and $F_{t}$ be a $k \times 1$ unobservable factors that summarize most of the information included in $X_{t}$. We assume that the joint dynamics of $\left(F_{t}, Y_{t}\right)$ are given by the following transition equation

$$
\left[\begin{array}{c}
F_{t} \\
Y_{t}
\end{array}\right]=\Phi^{*}(L)\left[\begin{array}{c}
F_{t-1} \\
Y_{t-1}
\end{array}\right]+v_{t} \Leftrightarrow \Phi(L)\left[\begin{array}{c}
F_{t} \\
Y_{t}
\end{array}\right]=v_{t}
$$

where $\quad \Phi(L)=I-\Phi^{*}(L) L=I-\Phi_{1} L-\ldots-$ $\Phi_{d} L^{d}$ is a suitable lag polynomial of finite order $d$. $\Phi_{j}$ is the coefficient matrix where $j=1, \ldots, d$ and the error term $v_{t}$ is mean zero with covariance matrix $Q$. Equation 1 is a VAR model although it consists of observable variables as well as unobservable ones.

In order to estimate Equation 1, it is assumed that the informational time series $X_{t}$ can be captured by the unobservable factors $F_{t}$ and the observed variables $Y_{t}$ by observation equation

$$
X_{t}=\Lambda^{f} F_{t}+\Lambda^{y} Y_{t}+e_{t}
$$

where $\Lambda^{f}$ is an $N \times k$ matrix of factor loadings, $\Lambda^{y}$ is $N \times M$ and $e_{t}$ is an $N \times 1$ vector of mean zero error terms. $e_{t}$ is allowed to be serially and weakly cross-sectionally uncorrelated by assumption. Here, we assume that $X_{t}$ does not depend on the lagged values of $F_{t}$. Next, we adopt the twostep principal components method that is employed by Bernanke et al. (2005) for the estimation.

For the identification of shocks, the Cholesky decomposition of the variance-covariance matrix of the estimated residuals is applied. The decomposition corresponds to causal ranking of the variables in the VAR such that the variable located last reacts simultaneously to all of the remaining variables and the preceding variable reacts simultaneously to all of the remaining variables excluding the last variable.

\section{Empirical evidence}

Our data set consists of series from Turkish CPI, HICP and D-PPI. The data span covers the period from February 1996 to April 2018. All series were transformed into the form of monthly percentage change to achieve stationarity. ${ }^{6}$ As a measure of electricity prices, we used monthly percentage change of electricity index of HICP (code: CP0451) and the same index taken from CPI indices (code: 0451). CPI and D-PPI data were obtained from the Turkish Statistical Institute,

\footnotetext{
${ }^{3}$ BP Statistical Review of World Energy $(2018,6)$ reports that the Turkish electricity generation growth rate was $8 \%$ in 2017.

${ }^{4}$ Electricity Market Development Report 2017 published by Republic of Turkey Energy Market Regulatory Authority reveals that the share of the natural gas in Turkish electricity production was 32.38\% in 2017.

${ }^{5}$ Gazprom (2018) indicates that in 2017, the Turkish share of the Russian natural gas exports accounts for $19 \%$ of Russia's total natural gas exports to Western European countries.

${ }^{6}$ We implemented a set of unit root tests in order to determine whether the series have unit root or not. Unit root tests indicate that the price growth series are all stationary. These tests are not reported here to save space.
} 
and HICP data were obtained from Eurostat. ${ }^{7}$ In the Appendix section, Table Al presents the descriptions of the series that are employed in our estimations.

In order to determine the number of factors, we use Bai and Ng's (2002) Factor Determination Test. The test statistics suggest that one factor explains more than $99 \%$ of the informational time series $X_{t}$ for both price series. Schwarz Information Criterion suggests the lag length of one for both specifications. Here, the FAVAR model incorporates 11 monthly seasonal dummies to account for seasonality. Eleven crisis dummies for August, September, October, November and December of 1999, November and December of 2000, January, February and March of 2001 and September of 2008 are also included.

Figure 1 reports the impulse responses for 29 $\mathrm{D}$-PPI components when one SD shock is given to the conditional mean of the standardized version of the electricity index of HICP for 12 months. The middle line represents the impulse response of a particular variable and the dotted lines represent the one-SD-confidence-interval. ${ }^{8}$ The $x$-axis represents the timeline and the $y$-axis represents the percentage response of a given standardized variable.

Table 1 reports the accumulated impulse responses for 12 periods for each of the 29 components of D-PPI Index when one SD shock is given to HICP electricity price. Note that we employed the analyses with the standardized data series. Thus, Table 1 ranks the group of components that are affected by electricity price shocks from the most to the least. Table 1 suggests that Machinery \& Equipment (not elsewhere classified); Electrical Equipment; and Rubber \& Plastic Products increase the most, while Tobacco

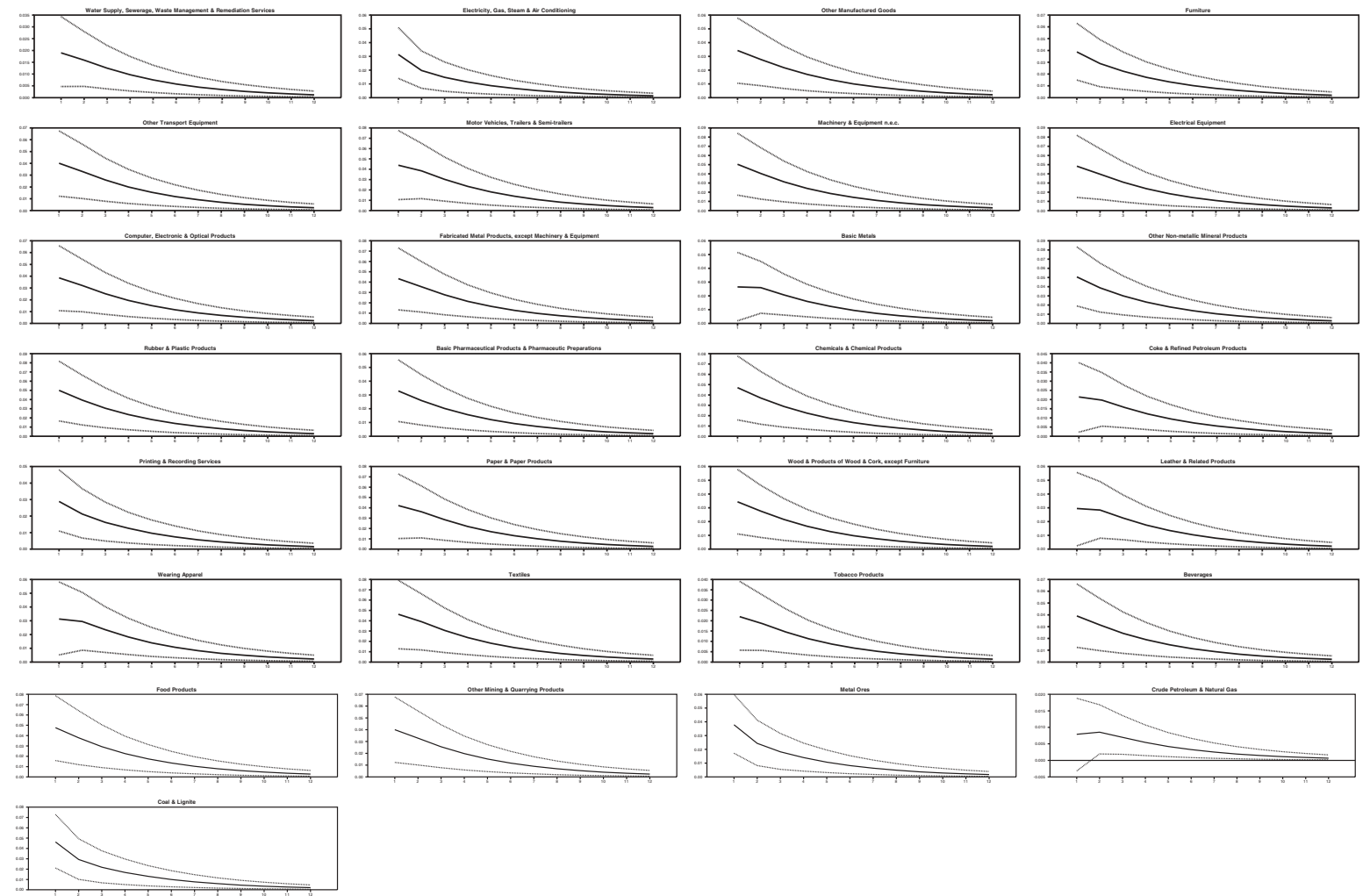

Figure 1. Impulse response functions of D-PPI components to HICP electricity price.

\footnotetext{
${ }^{7}$ There are no significant differences between Turkey's methodology as reported by Eurostat and related international standards. TSI employs NACE, Rev.2 classification procedure by using cash prices excluding value-added tax (VAT) and all relevant taxes in the calculation of D-PPI data series, and the base year of the series is 2003. All of the data were compiled by survey results (see Turkish Statistical Institute CPI Metadata definition).

${ }^{8}$ When the confidence interval contains the baseline, then we fail to reject the null hypothesis that there is no effect of electricity price innovations on that particular variable. In general, impulse response figures reveal that the shocks in the price of electricity increase all prices on different categories. Overall, the effect of shocks dies out after 5-7 months. Impulse response figures reported here are the supplementary material that is available from the authors upon request.
} 
Table 1. Accumulated responses of D-PPI components to HICP electricity price for the twelfth period.

\begin{tabular}{|c|c|}
\hline Machinery \& Equipment n.e.c. & $0.2172 *$ \\
\hline Electrical Equipment & $0.2130 *$ \\
\hline Rubber \& Plastic Products & $0.2128 *$ \\
\hline Other Non-metallic Mineral Products & $0.2107 *$ \\
\hline Textiles & $0.2087 *$ \\
\hline Motor Vehicles, Trailers \& Semi-trailers & $0.2045 *$ \\
\hline Food Products & $0.2037 *$ \\
\hline Chemicals \& Chemical Products & $0.2009 *$ \\
\hline Paper \& Paper Products & $0.1930 *$ \\
\hline Fabricated Metal Products, except Machinery \& Equipment & $0.1904 *$ \\
\hline Other Transport Equipment & $0.1778 *$ \\
\hline Other Mining \& Quarrying Products & $0.1758 *$ \\
\hline Computer, Electronic \& Optical Products & $0.1725 *$ \\
\hline Beverages & $0.1693 *$ \\
\hline Coal \& Lignite & $0.1637 *$ \\
\hline Furniture & $0.1576 *$ \\
\hline Wearing Apparel & $0.1553 *$ \\
\hline Other Manufactured Goods & $0.1501 *$ \\
\hline Electiricty & $0.1501 *$ \\
\hline Leather \& Related Products & $0.1494 *$ \\
\hline Wood \& Products of Wood \& Cork, except Furniture & $0.1486 *$ \\
\hline Basic Pharmaceutical Products \& Pharmaceutic Preparations & $0.1406 *$ \\
\hline Basic Metals & $0.1363 *$ \\
\hline Metal Ores & $0.1352 *$ \\
\hline Printing \& Recording Services & $0.1156 *$ \\
\hline Electricity, Gas, Steam \& Air Conditioning & $0.1100 *$ \\
\hline Coke \& Refined Petroleum Products & $0.1048 *$ \\
\hline Tobacco Products & $0.0994 *$ \\
\hline $\begin{array}{l}\text { Water Supply, Sewerage, Waste Management \& Remediation } \\
\text { Services }\end{array}$ & $0.0856 *$ \\
\hline Crude Petroleum \& Natural Gas & $0.0450 *$ \\
\hline
\end{tabular}

Notes: ${ }^{*}$ denotes the level of significance at $10 \%$ level. All the numbers are in percentages.
Table 2. Accumulated responses of D-PPI components to CPI electricity price for the twelfth period.

\begin{tabular}{ll}
\hline Machinery \& Equipment n.e.c. & $0.2168^{*}$ \\
Electrical Equipment & $0.2128^{*}$ \\
Rubber \& Plastic Products & $0.2126^{*}$ \\
Other Non-metallic Mineral Products & $0.2109^{*}$ \\
Textiles & $0.2082^{*}$ \\
Motor Vehicles, Trailers \& Semi-trailers & $0.2040^{*}$ \\
Food Products & $0.2036^{*}$ \\
Chemicals \& Chemical Products & $0.2011^{*}$ \\
Paper \& Paper Products & $0.1924^{*}$ \\
Fabricated Metal Products, except Machinery \& Equipment & $0.1903^{*}$ \\
Other Transport Equipment & $0.1777^{*}$ \\
Other Mining \& Quarrying Products & $0.1756^{*}$ \\
Computer, Electronic \& Optical Products & $0.1724^{*}$ \\
Beverages & $0.1692^{*}$ \\
Coal \& Lignite & $0.1646^{*}$ \\
Furniture & $0.1577 *$ \\
Wearing Apparel & $0.1549^{*}$ \\
Other Manufactured Goods & $0.1502^{*}$ \\
Electiricty & $0.1502^{*}$ \\
Leather \& Related Products & $0.1486^{*}$ \\
Wood \& Products of Wood \& Cork, except Furniture & $0.1485^{*}$ \\
Basic Pharmaceutical Products \& Pharmaceutic Preparations & $0.1408^{*}$ \\
Metal Ores & $0.1361^{*}$ \\
Basic Metals & $0.1356^{*}$ \\
Printing \& Recording Services & $0.1156^{*}$ \\
Electricity, Gas, Steam \& Air Conditioning & $0.1105^{*}$ \\
Coke \& Refined Petroleum Products & $0.1044^{*}$ \\
Tobacco Products & $0.0992^{*}$ \\
Water Supply, Sewerage, Waste Management \& Remediation & $0.0852^{*}$ \\
Services & \\
Crude Petroleum \& Natural Gas & $0.0446^{*}$ \\
\hline
\end{tabular}

Notes: ${ }^{*}$ denotes the level of significance at $10 \%$ level. All the numbers are in percentages.
Products; Crude Petroleum \&Natural Gas; and Water Supply, Sewerage, Waste Management \& Remediation Services increase the least. This is parallel to the understanding that the highly electricity-dependent sectors will respond to the shocks in the price of electricity more than the less electricity-dependent sectors.

We can also employ the similar analyses for standardized version of CPI electricity index as our shock variable on the 29 D-PPI components. These results are reported in Table 2. The results from both analyses imply that the previous results are robust.

Table 3 reports the results of the same exercises for each of the 12 components of HICP when one SD shock is given to HICP electricity price. Table 3 suggests that Housing, Water, Electricity, Gas
\& Other Fuels; Furnishings, Household Equipment \& Maintenance; and Restaurants \& Hotels increase the most, while Communications; Alcoholic Beverages, Tobacco \& Narcotics; and Education increase the least. This makes sense because intuitively, the components of HICP with high-demand elasticity of price will respond less to the shock in the price of electricity. Impulse response figures suggest that the shock in electricity price is significant for five periods for all of the variables in that estimation. ${ }^{9}$ Table 4 repeats the same analyses as we report in Table 3, but the shock variable is taken from the electricity index of CPI. The results from both analyses imply that the previous results are also robust. ${ }^{10}$

\footnotetext{
${ }^{9}$ We also conduct the same analyses for the components of CPI. Since the results from these analyses are not statistically significant and/or economically not intuitive, we do not report them in this study. The source of this limitation possibly stems from the failure to perfectly match the components of the two CPI series whose base years are 1994 and 2003. Only seven components of the CPI whose base year is 1994 matched perfectly with the CPI series whose base year is 2003 .

${ }^{10}$ Electricity prices and prices of other products might be responding to other variables related to the state of the economy, monetary policy and exchange rates. Thus, we repeat the same exercises such that we incorporate these variables into the system. We also include three macroeconomic series which are Weighted Average Overnight Interest Rate, Industrial Production growth Rate and US Dollar Selling Rates as percentage change from the previous period that are obtained from The Central Bank of the Republic of Turkey and Bloomberg. Since there is only a slight change in terms of the order of magnitude and magnitude itself after incorporating these macroeconomic series into the system, these tables also indicate the robustness of our analyses.
} 
Table 4. Accumulated responses of HICP components to CPI electricity price for the twelfth period.

\begin{tabular}{ll}
\hline Housing, Water, Electricity, Gas \& Other Fuels & $0.3786 *$ \\
Furnishings, Household Equipment \& Maintenance & $0.2823 *$ \\
Restaurants \& Hotels & $0.2481 *$ \\
Electricity & $0.2481 *$ \\
Miscellaneous Goods \& Services & $0.2216 *$ \\
Transport & $0.2060 *$ \\
Recreation \& Culture & $0.1813 *$ \\
Food \& Nonalcoholic Beverages & $0.1610 *$ \\
Clothing \& Footwear & $0.1318 *$ \\
Health & $0.1078 *$ \\
Education & $0.0876 *$ \\
Alcoholic Beverages, Tobacco \& Narcotics & $0.0569 *$ \\
Communications & $0.0346 *$ \\
\hline Notes: ${ }^{*}$ denotes the level of significance at 10\% level. All the numbers are \\
in percentages.
\end{tabular}

Table 3. Accumulated responses of HICP components to HICP electricity price for the twelfth period.

\begin{tabular}{lr}
\hline Housing, Water, Electricity, Gas \& Other Fuels & $0.3755^{*}$ \\
Furnishings, Household Equipment \& Maintenance & $0.2803^{*}$ \\
Restaurants \& Hotels & $0.2450^{*}$ \\
Electricity & $0.2450^{*}$ \\
Miscellaneous Goods \& Services & $0.2214 *$ \\
Transport & $0.2040^{*}$ \\
Recreation \& Culture & $0.1806^{*}$ \\
Food \& Nonalcoholic Beverages & $0.1590^{*}$ \\
Clothing \& Footwear & $0.1317 *$ \\
Health & $0.1066^{*}$ \\
Education & $0.0870 *$ \\
Alcoholic Beverages, Tobacco \& Narcotics & $0.0561 *$ \\
Communications & $0.0342 *$ \\
\hline Notes: * denotes the level of significance at 10\% level. All the numbers are \\
in percentages.
\end{tabular}

\section{Conclusion}

This article employs a novel method on the linkage between movements in the price of electricity and prices of other goods and services. The results from the analyses on the components of D-PPI suggest that Machinery \& Equipment (not elsewhere classified); Electrical Equipment; and Rubber \& Plastic Products increase the most, while Tobacco Products; Crude Petroleum \& Natural Gas; and Water Supply, Sewerage, Waste Management \& Remediation Services increase the least. Furthermore, the results from the analyses on components of HICP suggest that Housing, Water, Electricity, Gas \& Other Fuels; Furnishings, Household Equipment \& Maintenance; and
Restaurants \& Hotels increase the most, while Communications; Alcoholic Beverages, Tobacco \& Narcotics; and Education increase the least. The components that have higher electricity price responses are the sectors that are more capital intensive and have higher electricity consumption per unit of output.

\section{Disclosure statement}

No potential conflict of interest was reported by the authors.

\section{ORCID}

Berument M. Hakan (D) http://orcid.org/0000-0003-22764741

\section{References}

Akkemik, K. A. 2011. "Potential Impacts of Electricity Price Changes on Price Formation in the Economy: A Social Accounting Matrix Price Modeling Analysis for Turkey." Energy Policy 39 (2): 854-864. doi:10.1016/j. enpol.2010.11.005.

Bai, J., and S. Ng. 2002. "Determining the Number of Factors in Approximate Factor Models." Econometrica 70 (1): 191-221. doi:10.1111/ecta.2002.70.issue-1.

Bernanke, B. S., J. Boivin, and P. Eliasz. 2005. "Measuring the Effects of Monetary Policy: A Factor Augmented Vector Autoregressive (FAVAR) Approach." The Quarterly Journal of Economics 120 (1): 387-422.

BP. 2018. Statistical Review of World Energy 67th Edition.

Central Bank of the Republic of Turkey. 2018. Inflation Report 2018-III.

Gazprom. 2018. "Delivery Statistics.” August 2018. http:// www.gazpromexport.ru/en/statistics/

He, Y. X., S. L. Zhang, L. Y. Yang, Y. J. Wang, and J. Wang. 2010. "Economic Analysis of Coal Price-Electricity Price Adjustment in China Based on the CGE Model." Energy Policy 38 (11): 6229-6637. doi:10.1016/j.enpol.2010.06.033.

Lim, S.-Y., and S.-H. Yoo. 2013. "The Impact of Electricity Price Changes on Industrial Prices and the General Price Level in Korea.” Energy Policy 61: 1551-1555. doi:10.1016/ j.enpol.2013.06.129.

Mjelde, J. W., and D. A. Bessler. 2009. "Market Integration among Electricity Markets and Their Major Fuel Source Markets." Energy Economics 31 (3): 482-491. doi:10.1016/ j.eneco.2009.02.002.

Stock, J. H., and M. W. Watson 1998. "Diffusion Indexes." National Bureau of Economic Research. Working Paper No. 6702. 


\section{Appendix}

Table A1. Data description.

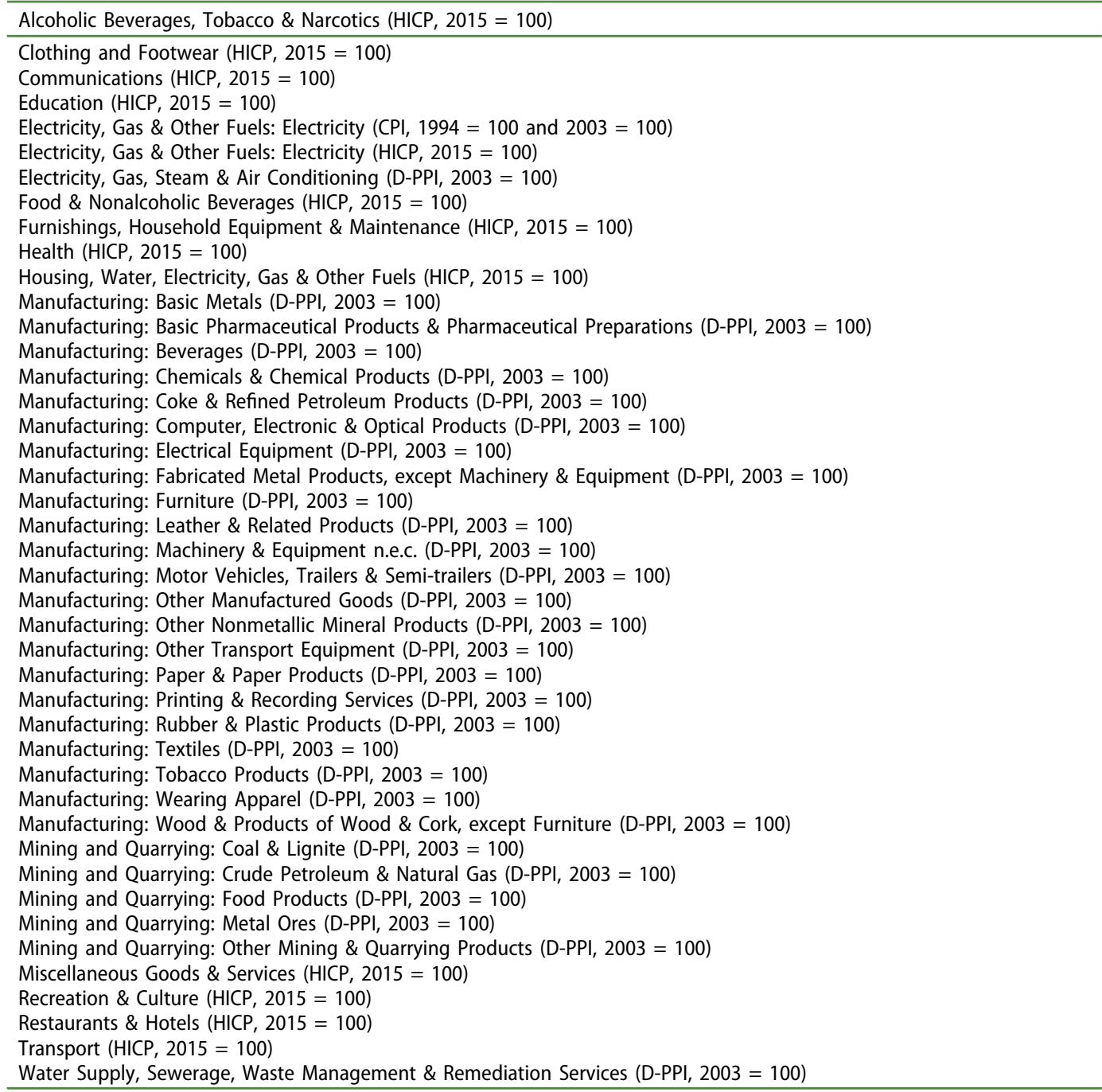

